\title{
Development of Broadband High-Frequency Piezoelectric Micromachined Ultrasonic Transducer Array
}

\author{
Xu-Bo Wang ${ }^{1}{ }^{\circledR}$, Le-Ming He ${ }^{1}{ }^{1}$, You-Cao Ma ${ }^{1}$, Wen-Juan Liu ${ }^{1,2}$, Wei-Jiang Xu ${ }^{2,3}{ }^{\circledR}$, Jun-Yan Ren ${ }^{1}$, \\ Antoine Riaud ${ }^{1}$ and Jia Zhou ${ }^{1, *(D)}$ \\ 1 State Key Laboratory of ASIC and System, School of Microelectronics, Fudan University, \\ Shanghai 201203, China; xbwang16@fudan.edu.cn (X.-B.W.); arthur.lmhe@gmail.com (L.-M.H.); \\ ycma19@fudan.edu.cn (Y.-C.M.); 14110720053@fudan.edu.cn (W.-J.L.); jyren@fudan.edu.cn (J.-Y.R.); \\ antoine_riaud@fudan.edu.cn (A.R.) \\ 2 Univ. Polytechnique Hauts-de-France, CNRS, Univ. Lille, Centrale Lille, UMR 8520-IEMN, DOAE, \\ F-59313 Valenciennes, France; wei-jiang.xu@uphf.fr \\ 3 INSA Hauts-de-France, Le Mont Houy, F-59313 Valenciennes, France \\ * Correspondence: jia.zhou@fudan.edu.cn
}

Citation: Wang, X.-B.; He, L.-M.; Ma, Y.-C.; Liu, W.-J.; Xu, W.-J.; Ren, J.-Y.; Riaud, A.; Zhou, J. Development of Broadband High-Frequency

Piezoelectric Micromachined Ultrasonic Transducer Array. Sensors 2021, 21, 1823. https://doi.org/ $10.3390 / \mathrm{s} 21051823$

Received: 7 February 2021

Accepted: 4 March 2021

Published: 5 March 2021

Publisher's Note: MDPI stays neutral with regard to jurisdictional claims in published maps and institutional affiliations.

Copyright: (C) 2021 by the authors. Licensee MDPI, Basel, Switzerland. This article is an open access article distributed under the terms and conditions of the Creative Commons Attribution (CC BY) license (https:/ / creativecommons.org/licenses/by/ $4.0 /)$.

\begin{abstract}
Piezoelectric micromachined ultrasonic transducers (PMUT) are promising elements to fabricate a two-dimensional (2D) array with a pitch small enough (approximately half wavelength) to form and receive arbitrary acoustic beams for medical imaging. However, PMUT arrays have so far failed to combine the wide, high-frequency bandwidth needed to achieve a high axial resolution. In this paper, a polydimethylsiloxane (PDMS) backing structure is introduced into the PMUTs to improve the device bandwidth while keeping a sub-wavelength $(\lambda)$ pitch. We implement this backing on a $16 \times 8$ array with $75 \mu \mathrm{m}$ pitch $(3 \lambda / 4)$ with a $15 \mathrm{MHz}$ working frequency. Adding the backing nearly doubles the bandwidth to $92 \%(-6 \mathrm{~dB})$ and has little influence on the impulse response sensitivity. By widening the transducer bandwidth, this backing may enable using PMUT ultrasonic arrays for high-resolution 3D imaging.
\end{abstract}

Keywords: high-frequency; wide bandwidth; PMUT; PZT; PDMS; micromachining; two-dimensional array; rangefinder

\section{Introduction}

Two-dimensional (2D) phased arrays are foreseen to revolutionize medical imaging with high frame rate, high scanning accuracy, and dynamic focusing [1]. Compared with bulk ultrasonic transducers, the micro-machined ultrasonic transducers (MUTs) are easy to fabricate even for high acoustic frequencies (over $10 \mathrm{MHz}$ ) [2], can be produced in large arrays with a small footprint [3], and mostly have high process compatibility with standard integrated circuit production [4]. Therefore, MUTs are promising elements for high-frequency 2D phased arrays. MUTs are divided into capacitive-based transducers (CMUTs) and piezoelectric-based transducers (PMUTs). Compared to CMUT, PMUTs have a more simple structure and thus a robust fabrication process [5], generate higher acoustic beam intensity, and do not require any bias voltage, which is preferred in medical applications [6]. However, the bandwidth of PMUTs is very limited and precludes the device from most imaging applications, including pulse-echo imaging and those involving chirp waveforms or harmonic response applications [7].

Several approaches exist to overcome this limitation. In mode-merging [8], a device with an appropriate structure design, such as a ring [7] or ribbon [9] shape, can generate two or more resonance peaks and overlap in one broad bandwidth, often exceeding 100\% $(-6 \mathrm{~dB})$. However, such devices are challenging to design for high frequency (because the resonance peaks become relatively narrower) and the overlapping effect is sensitive to the mass density of the load [7]. Another approach better suited for high-frequency 
applications is using parallel multiple resonator cells with different working frequencies to form an effective element [10]. The independent resonance peaks overlap into one under load and get a large bandwidth at high frequency [11]. However, there exist two drawbacks in its further imaging applications: (i) an acoustic lens is needed to focus the beam produced by all the parallel cells [12], and (ii) the juxtaposition of many elements is hardly compatible with the pitch requirement of a 2D phased array, which limits the steering range. In summary, the existing technology cannot be applied to get a highfrequency broad bandwidth 2D PMUTs phased array.

In bulk devices, the bandwidth is increased without changing the element size by adding a backing layer. Such a layer requires high attenuation and good acoustic matching with the vibrating element [13]. To the best of our knowledge, this backing solution has never been applied to high-frequency PMUTs. This may be down to the specific requirements of PMUTs compared to bulk devices. First, the backing layer fabrication process must be compatible with microfabrication techniques. Second, because PMUTs rely on a flexural vibration mode and have an acoustic impedance close to water or human tissues, the backing impedance must also match that of water (unlike PZT for bulk elements).

PDMS is selected as the backing material for the following reasons. Firstly, PDMS has low surface energy and easily fills delicate structures under vacuum [14]. Secondly, the relatively soft PDMS works as an extra load without changing the plate flexural vibration mode to the thickness mode as bulk devices do. Thirdly, the acoustic properties of PDMS, including attenuation, are well characterized, and the properties can be potentially changed by modifying composition or adding particles, such as tungsten microspheres [15], as required.

In this paper, we demonstrate a backed PMUTs (BPMUTs) with a pitch of $3 \lambda / 4$. The backing layer is obtained by deep silicon etching and PDMS backfilling into the etched blind hole (cavity). After describing the device fabrication and structure, we measure the resulting vibration mode of the B-PMUT, the equivalent damping effect and attenuation of the PDMS backing structure, and the pulse response sensitivity of the B-PMUT. Finally, the 2D array is compared to the existing literature in terms of pitch, frequency, and bandwidth.

\section{Materials and Methods}

\subsection{Design and Fabrication}

The structure of the device is shown in Figure 1a, and the multilayered structure is composed of, from top to bottom, a top electrode, a lead-zirconate-titanate (PZT) piezoelectric layer, a vibration diaphragm (including bottom electrode, insulating silicon oxide film, single crystal $\mathrm{Si}$, and buried silicon oxide layer), cavity structure, and PDMS backing. The array consists of $16 \times 8$ elements with a $75 \mu \mathrm{m}$ pitch $(3 \lambda / 4$, at $15 \mathrm{MHz}$ in water), as shown in Figure 1b [16]. The corresponding structure parameters are listed in Table 1.

(a)

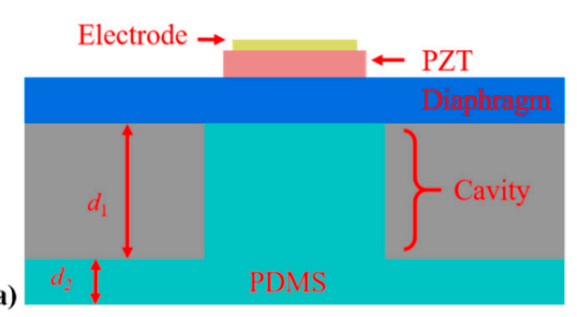

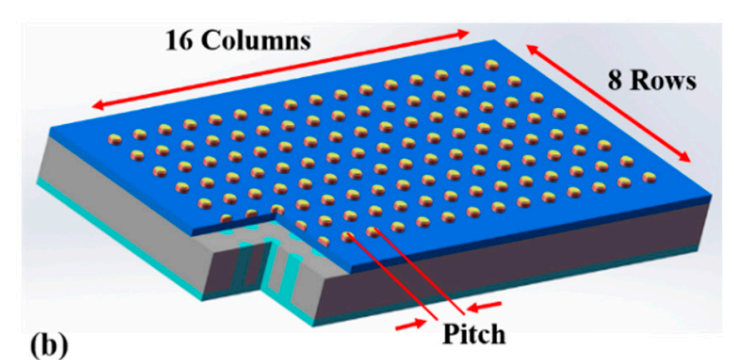

(b)

Figure 1. Schematic of backed piezoelectric micromachined ultrasonic transducers (B-PMUTs). (a) The designed structure of a single element. (b) Three-dimensional (3D) schematic of the array. 
Table 1. The structure parameters.

\begin{tabular}{cccc}
\hline Name & Value $(\mu \mathrm{m})$ & Name & Value $(\boldsymbol{\mu m})$ \\
\hline Electrode diameter & 28 & Cavity diameter & 40 \\
\hline PZT diameter & 32 & Cavity depth $\left(d_{1}\right)$ & 300 \\
PZT thickness & 1 & PDMS thickness $\left(d_{1}+d_{2}\right)$ & 330 \\
Diaphragm thickness & 4.7 & Pitch & 75 \\
\hline
\end{tabular}

The fabrication process is shown in the following panels in Figure 2. (a) A four inches silicon-on-insulator (SOI) wafer with a $4 \mu \mathrm{m}$ device layer (single crystal $\mathrm{Si}$ ) and a $500 \mathrm{~nm}$ buried oxide layer is wet oxidized at $1100{ }^{\circ} \mathrm{C}$ to get $500 \mathrm{~nm}$ thermal oxide layers on both sides. (b) The wafer is back-grinded to $300 \mu \mathrm{m}$, and then $20 \mathrm{~nm} / 200 \mathrm{~nm}$ of Ti/Pt is deposited by physical vapor deposition (PVD) as the bottom electrode, after which a $1 \mu \mathrm{m}$ PZT film is spin-coated by a multilayer sol-gel process. The PZT thin film deposition is finished by a commercial company (ZILM Co., http:/ / www.zilm-tech.com/, accessed on 7 February 2021). (c) The $10 \mathrm{~nm} / 100 \mathrm{~nm} \mathrm{Cr} / \mathrm{Au}$ top electrode is deposited by PVD and patterned via the lift-off process. (d) The PZT film is patterned via wet etching with positive photoresist (RZJ-304) as a mask. By exposing the wafer to a 20:6:1 mixture of deionized water /hydrochloric acid/buffered oxide etchant (BOE, 6:1) with stirring, and immediately followed by a vigorous rinsing in DI water, cylinder-like islands are obtained with $40 \mathrm{~s}$ etch for $1 \mu \mathrm{m}$ PZT at room temperature. (e) A $250 \mathrm{~nm}$ silicon oxide layer is deposited at $300{ }^{\circ} \mathrm{C}$ (below the curie point of PZT) to be the insulation and passivation layer using plasma-enhanced chemical vapor deposition (PECVD). (f) For wire contact, a via hole is etched using reactive ion etching (RIE). (g) A metal stack of $20 \mathrm{~nm}$ chromium and $200 \mathrm{~nm}$ gold is patterned by lift-off to be the lead wires and pads. (h) The device layer is released by deep reactive ion etching (DRIE) from the backside of the wafer, and a cavity of depth $d_{1}=300 \mu \mathrm{m}$ is remaining. (i) The backing is formed by pouring a 10:1 polydimethylsiloxane (PDMS) mixture (Sylgard 184, Dow Corning Co., Midland, TX, USA) into the opening end of the cavity and placing the chip in a vacuum (below $133 \mathrm{~Pa}$ ) to let the silicone spontaneously fill the cavity. Most of the excess PDMS is eliminated by spin-coating, and the remaining forms a thin film of thickness $d_{2}=30 \mu \mathrm{m}$. After curing, the PDMS fits tightly with the PMUT diaphragm and forms a thin layer over the whole SOI substrate.

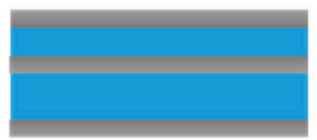

(a)

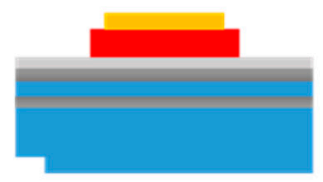

(d)

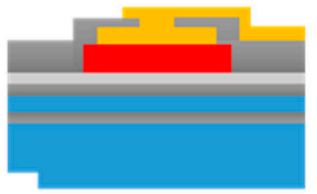

$(\mathrm{g})$

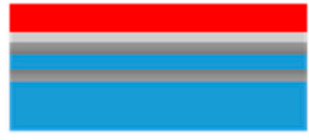

(b)

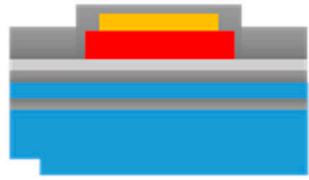

(e)

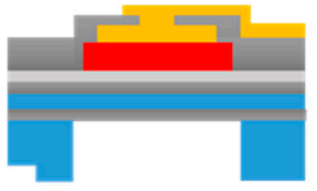

(h)

$\mathrm{Si}$

$\mathrm{Au} / \mathrm{Cr}$

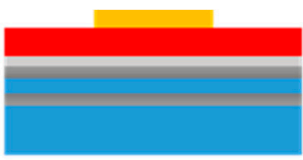

(c)

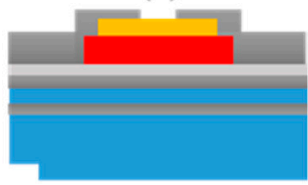

(f)

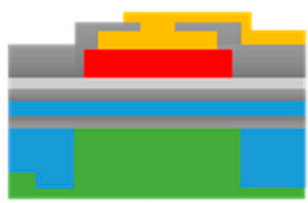

(i)

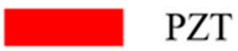

PZT

PDMS

Figure 2. (a-i) The fabrication process of the B-PMUTs. 
The chip is zoomed-in and shown in Figure 3a; the array consists of $16 \times 8$ addressable elements, and each element can be driven independently for future phase control. Figure $3 b, c$ show the SEM cross-section of the typical element without and with PDMS filling, respectively. The PZT layer and Si diaphragm on an SOI substrate with a deeply etched cavity are visible, and the diameter of the cavity is $40 \mu \mathrm{m}$.
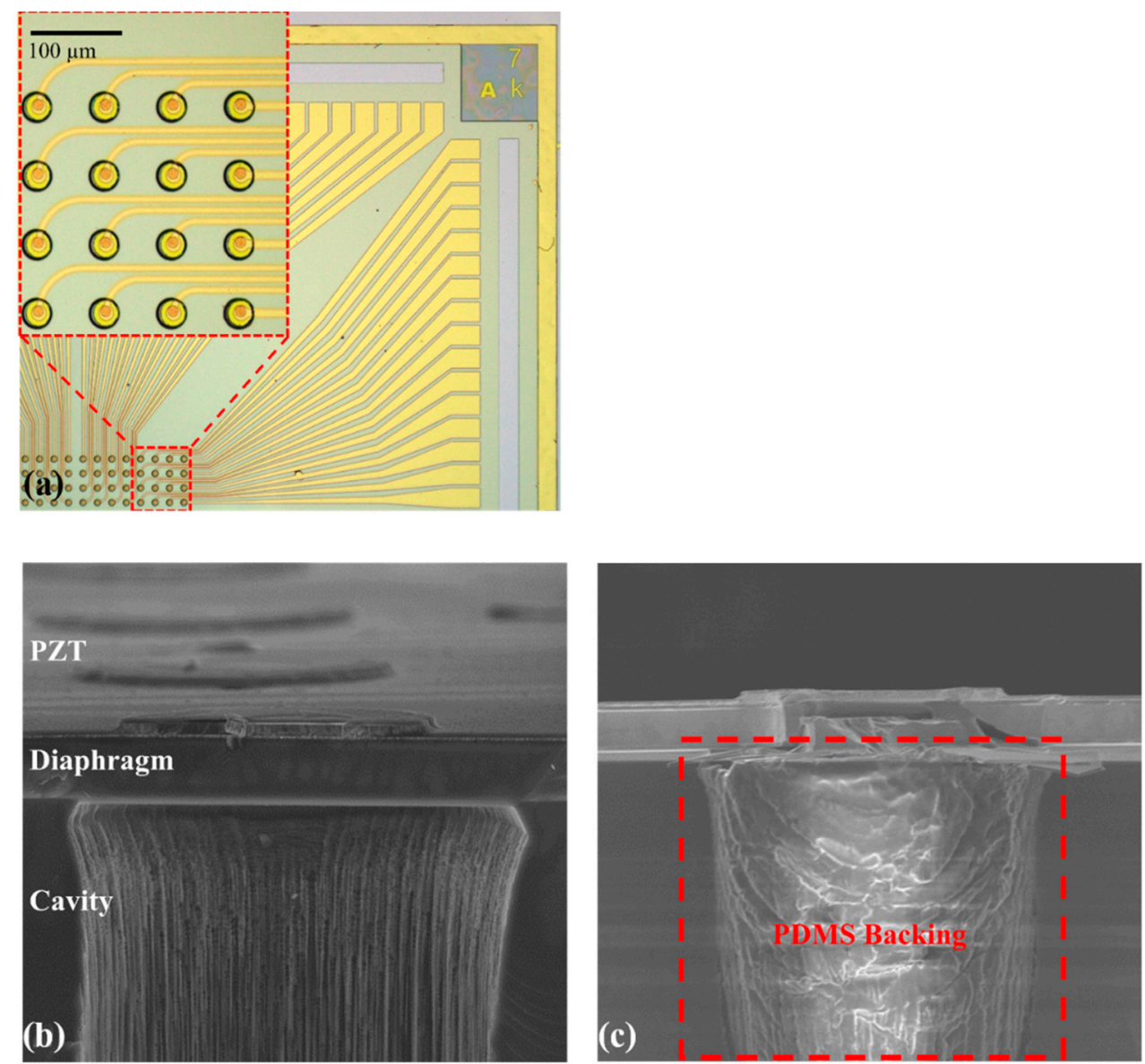

Figure 3. Microscopy pictures of B-PMUTs. (a) Top view of a part of $16 \times 8$ PMUTs arrays. (b) Cross-sectional SEM image of a typical element without PDMS backing. (c) Cross-sectional SEM image of the element with PDMS filling.

\subsection{Experimental Setup}

To verify the performance of the PDMS backing, the devices of B-PMUTs are compared to a control group without PDMS backing (C-PMUTs). The two groups of devices are fabricated in the same batch; i.e., the only difference between them is with and without the backing layer.

We first analyze the effect of PDMS on the dissipation and loading of the PMUT membrane based on the steady-state responses of the B- and C-PMUTs in air and then in water. In this experiment, a $4 \mathrm{~V}_{\mathrm{pp}} 100$-cycles sine wave is used as the excitation signal. Then, to verify that the thickness of PDMS is enough and suitable to absorb the rear reflection, we measure the effect of dissipation of the baking layer on the pulse responses of the B-PMUTs in air (to eliminate the additional loading due to water that may enhance the bandwidth). In this experiment, the devices are tested with a $10 \mathrm{~ns}$-long $30 \mathrm{~V}$ pulse, which is generated by an arbitrary function generator (Tektronix AFG3100) and an amplifier (Mini-circuits ZHL-5W-1+). The vibration of the diaphragm in the experiment is measured by a scanning heterodyne laser Doppler vibrometer (LDV) [17] and analyzed in the Python environment. The experimental setup is shown in Figure 4. Finally, we quantify the improvement in pulse sensitivity and bandwidth in a more realistic setting by comparing the pulse response 
in water with and without backing. The test method is in accordance with that in the dissipation measurement.

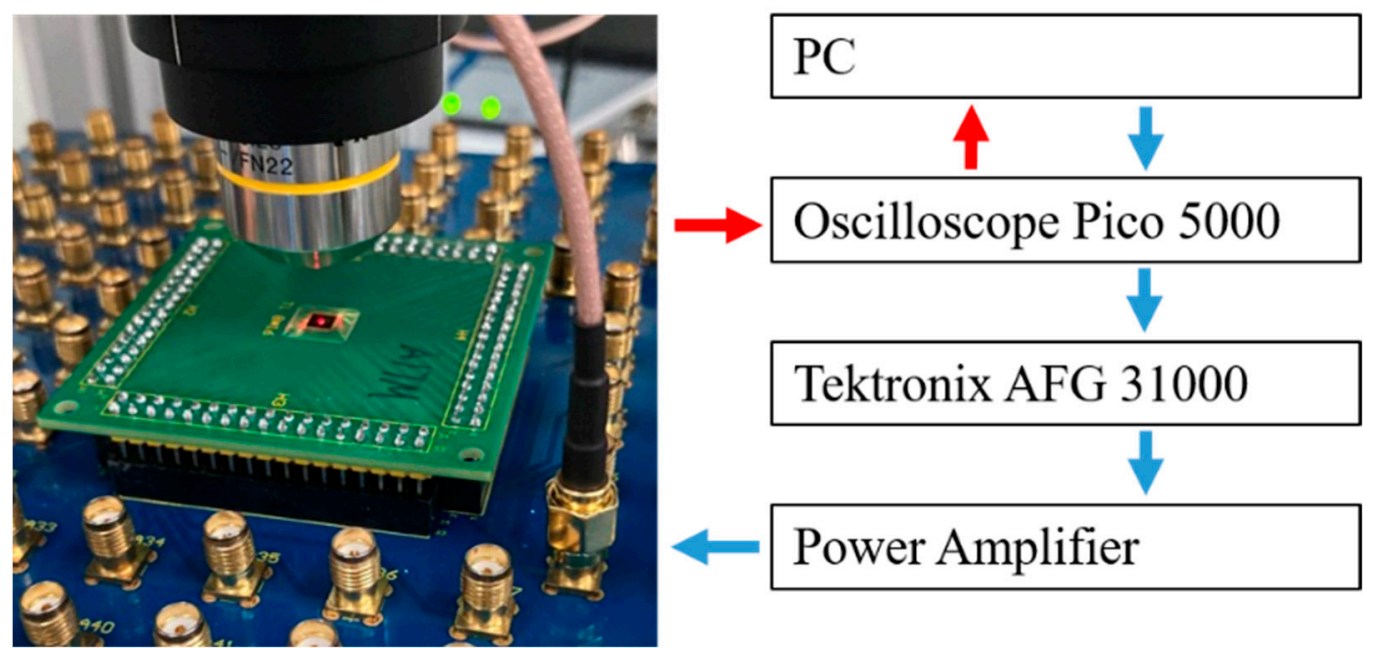

Figure 4. Laser Doppler vibrometer (LDV) setup for characterizing the PMUT performance.

\section{Results and Discussion}

\subsection{Steady-State Response}

In air, the resonant frequency of the C-PMUT is $20.2 \mathrm{MHz}$ with a displacement amplitude of $36.6 \mathrm{~nm}$ at the center of the tested element. In the same condition, the resonant frequency of the B-PMUT is $19.0 \mathrm{MHz}$ with an amplitude of $9.2 \mathrm{~nm}$.

The vibration results of the two group devices working under water load are shown in Figure 5. It can be seen that the two group devices are working in the same flexural vibration mode. Due to water loading, the resonant frequency of the C-PMUT is reduced to $16.4 \mathrm{MHz}$ with the peak amplitude decreasing to $3.7 \mathrm{~nm}$, which is about $10 \%$ of that in air. Similarly to the C-PMUT, the resonance frequency of the B-PMUT decreases to $15.3 \mathrm{MHz}$ with the peak amplitude down to $1.9 \mathrm{~nm}$, which is about $20 \%$ of that in air. The difference between C-PMUT and B-PMUT is coming from the additional PDMS backing.
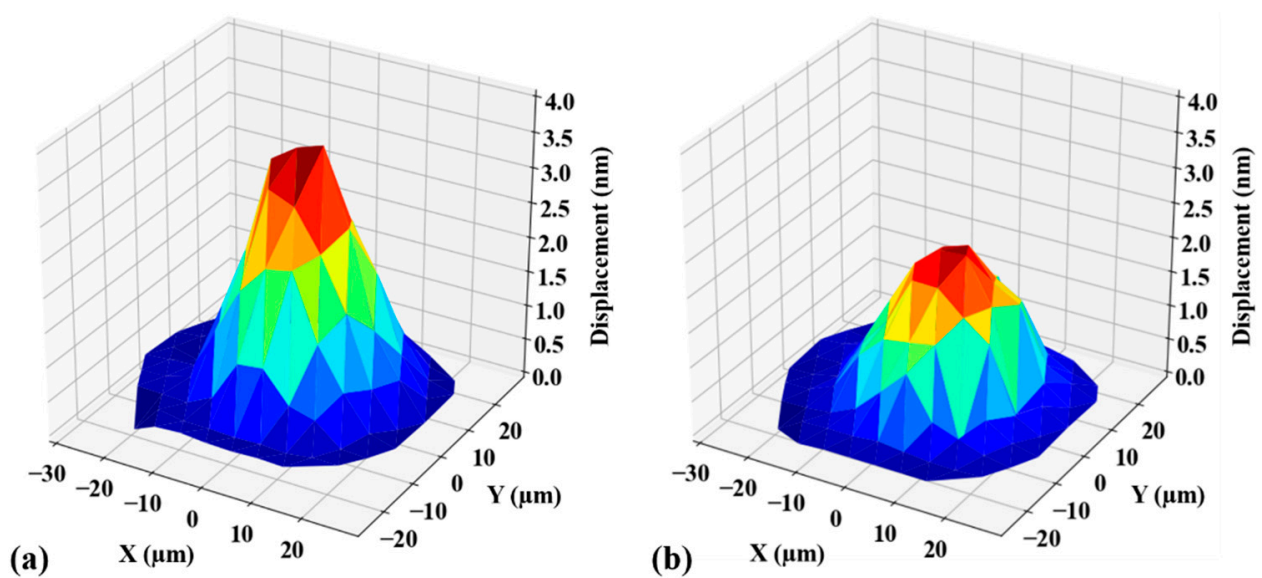

Figure 5. The first resonance mode of the devices working under water load for (a) a control group without PDMS backing (C-PMUT) and (b) B-PMUT.

To analyze the role of backing in the vibration process, the vibration of C-PMUT and B-PMUT in water load is fitted with an equivalent point-mass model in the form of $m \ddot{Z}+b \dot{Z}+k Z=F_{0} \mathrm{e}^{\mathrm{j} \omega t}$, where $m, b, k, F_{0}$ are the equivalent mass, damping, stiffness, and piezoelectric driving force, respectively [10]. We obtain the value of these parameters from 
static and steady-state experiments, with $k=F_{0} / A_{Q}, b=F_{0} /\left(A_{D} \omega_{0}\right)$, and $m=k / \omega_{0}^{2}$, where $A_{\mathrm{Q}}$ is static displacement (C-PMUT and B-PMUT are found experimentally to share the same $\left.A_{\mathrm{Q}}\right), A_{\mathrm{D}}$ is steady-state displacement, and $\omega_{0}$ is resonance angular frequency. Numerically, the ratio of equivalent parameters of C-PMUT and B-PMUT in water load are $k_{C} / k_{B}=1, b_{C} / b_{B}=0.47$, and $m_{C} / m_{B}=0.87$. This indicates that after adding the PDMS backing, the equivalent stiffness of the system is kept constant, the equivalent mass is increased by $15 \%$, and the equivalent damping is doubled. Thus, the additional PDMS is backing half the Q-factor of the system.

\subsection{Attenuation of PDMS Backing}

The PDMS backing should be long enough to absorb the reflection wave from the rear face. Otherwise, it would disturb the measurement results of the impulse reponse. The attenuation effect of a $300 \mu \mathrm{m}$ PDMS backing layer is tested in air, in which case the backing layer is the only way for reflection. As shown in Figure 6, the peak displacement amplitude is $33.2 \mathrm{~nm}$ at $2.46 \mu \mathrm{s}$, and no evident echoes are recorded after that.

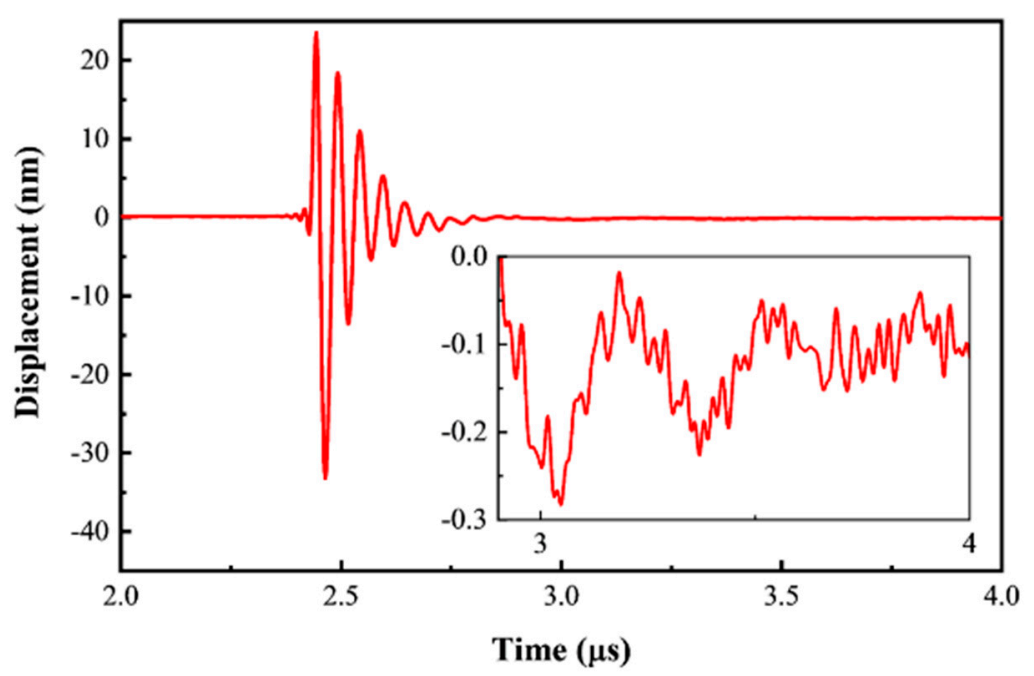

Figure 6. Peak displacement at the center of a B-PDMS element tested in air with a $10 \mathrm{~ns} 30 \mathrm{~V}$ pulse. The insert figure shows the detailed response from 2.9 to $4 \mu \mathrm{s}$.

There could be two reflections of the transmitted sound waves from the rear face. The first one occurs at the edge of the cavity, and the second one is $30 \mu \mathrm{m}$ farther at the interface between the PDMS film and the air [18]. Considering the longitudinal velocity of PDMS (v) is about $1028 \mathrm{~m} / \mathrm{s}$ [19], the two reflection disturbances should act on the vibration plate after $2 d_{1} / v=0.58 \mu \mathrm{s}$ and $2\left(d_{1}+d_{2}\right) / v=0.64 \mu \mathrm{s}$ of the generation, respectively, which means that if they existed, both should appear after $3 \mu \mathrm{s}$. However, as shown in the insert of Figure 6, only a low-frequency wave $(0.5 \mathrm{MHz})$ can be seen, which is possibly due to the thermal expansion of the PDMS [20]. No disturbance with a frequency higher than $5 \mathrm{MHz}$ and peak-to-peak value higher than $0.1 \mathrm{~nm}$ is observed. Therefore, it can be deduced that the $300 \mu \mathrm{m}$ PDMS backing structure can attenuate the reflected wave by at least $55 \mathrm{~dB}$. This is much higher than the $7 \mathrm{~dB}$ attenuation of longitudinal waves in bulk [19], suggesting a complex propagation in the cylinder.

\subsection{Impulse Response}

To analyzed the improvement of PDMS backing on the bandwidth, the impulse response of C-PMUT and B-PMUT are tested and compared. In Figure 7, the time-dependent displacement and the corresponding spectrum are shown in solid red line and dashed blue line, respectively. The experiment results are concluded in Table 2. 

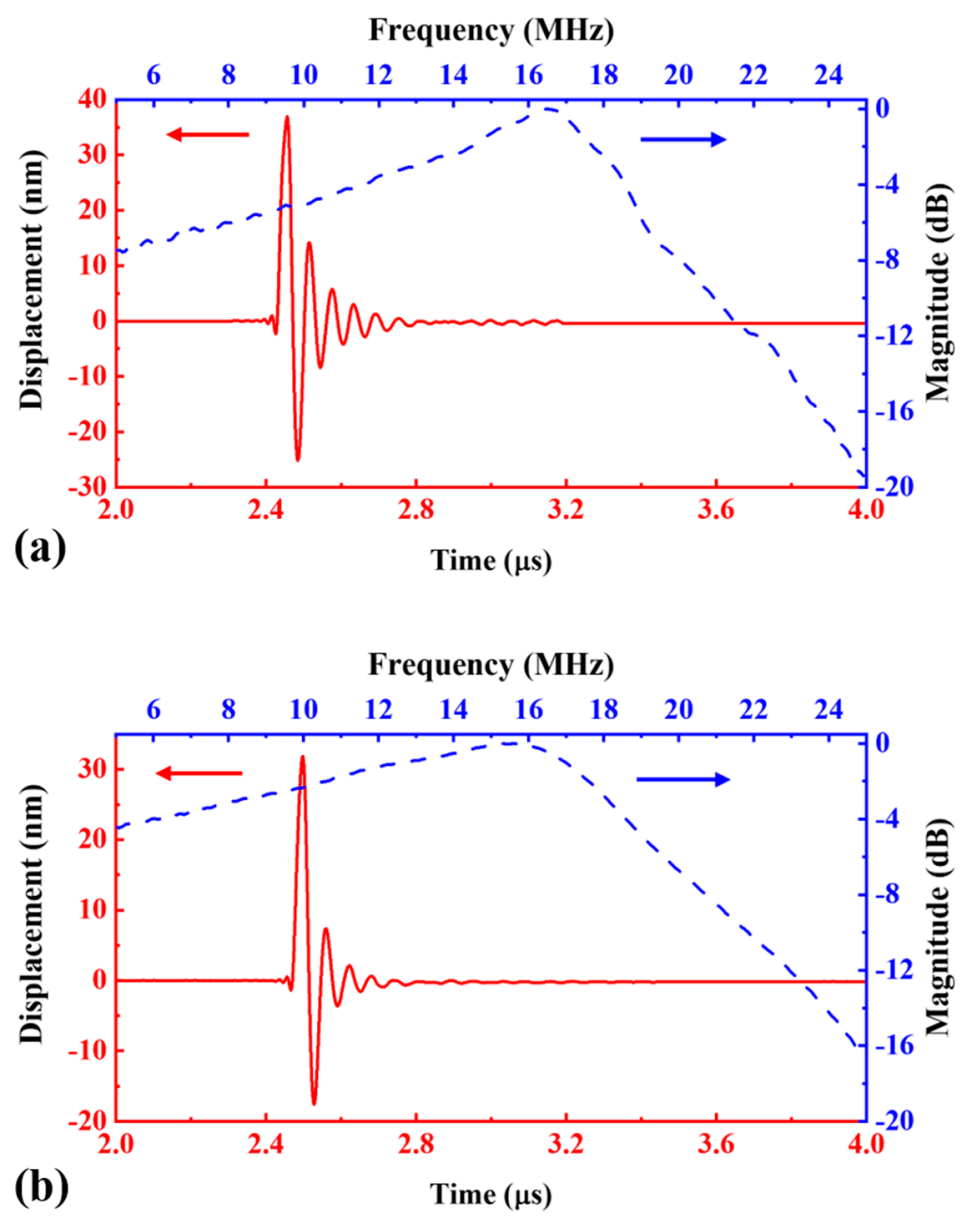

Figure 7. Vibration response of (a) C-PMUT and (b) B-PMUT, tested in water with a $10 \mathrm{~ns} 30 \mathrm{~V}$ pulse. The time-domain response is shown with a red solid line, and the frequency-domain response is shown with a blue dash line.

Table 2. Impulse responses of C-PMUT and B-PMUT.

\begin{tabular}{cccccccccc}
\hline \multirow{2}{*}{ Device } & \multicolumn{2}{c}{$\begin{array}{c}\text { Displacement } \\
(\mathbf{n m})\end{array}$} & \multicolumn{2}{c}{$\begin{array}{c}\text { Ringdown Time } \\
(\mathbf{n s})\end{array}$} & \multicolumn{2}{c}{$\begin{array}{c}\text { Center Frequency } \\
(\mathbf{M H z})\end{array}$} & \multicolumn{2}{c}{$\begin{array}{c}\text { Bandwidth } \\
(@-3 \mathbf{d B})\end{array}$} \\
\cline { 2 - 10 } & Air & Water & Air & Water & Air & Water & Air & Water \\
\hline C-PMUT & 38.9 & 36.9 & 1710 & 160 & 20.2 & 16.5 & $6 \%$ & $32 \%$ \\
\hline B-PMUT & 33.2 & 31.8 & 182 & 62 & 19.4 & 15.6 & $22 \%$ & $63 \%$ \\
\hline
\end{tabular}

With water load, as shown in Figure 7a, the center frequency of C-PMUT is $16.5 \mathrm{MHz}$, and the peak amplitude is $36.9 \mathrm{~nm}$, which is $94 \%$ of that in air, yielding a sensitivity of $1.2 \mathrm{~nm} / \mathrm{V}$. The decrease is not as much as that in the steady state because the peak amplitude of the impulse response is a synthesis of broadband response in transient. However, the fractional bandwidth increases sharply to $32 \% @-3 \mathrm{~dB}$. This is because the water load increases the energy loss of the vibration system. The ringdown time is $160 \mathrm{~ns} @-20 \mathrm{~dB}$. For the B-PMUT, as shown in Figure $7 \mathrm{~b}$, the center frequency is $15.6 \mathrm{MHz}$, which is $94.5 \%$ of that of C-PMUT. The peak amplitude is $31.8 \mathrm{~nm}$, which is $86 \%$ of that of C-PMUT. The corresponding sensitivity is $1.1 \mathrm{~nm} / \mathrm{V}$. The above results indicate that the PDMS backing layer has little influence on the center frequency and pulse sensitivity. We think this is because the acoustic impedance of PDMS backing is matching with the impedance of water. The bandwidth of the B-PMUT is twice that of the control group, which is $63.4 \%$ $@-3 \mathrm{~dB}(92 \% @-6 \mathrm{~dB})$, and the ringdown time falls to $62 \mathrm{~ns}$. This variation is favorable for 
medical imaging, and it is in accordance with the Q-factor predicted by the model given in Section 3.1.

Figure 8 compares the characteristics of published PMUTs with the B-PMUT presented here for the potential of imaging. The figure is divided into low frequency (left) and highfrequency quadrants (right) according to the center frequency $(10 \mathrm{MHz})$, and the right side is further developed into three quadrants depending on the dimensionless pitch (the ratio of pitch to the wavelength at a center frequency in the corresponding medium) [2,4,21]. The region between the yellow and red line is suitable for a $2 \mathrm{D}$ array, and the red line is the most ideal state for a phased array with an arbitrary steer angle [22]. Note that smaller pitches would not improve further the resolution for propagative waves. Compared with the devices in the right part, the B-PMUT moves closer to the red line, and while keeping a high bandwidth, nearly twice that of the counterpart [2], which promises higher axial resolution in imaging.

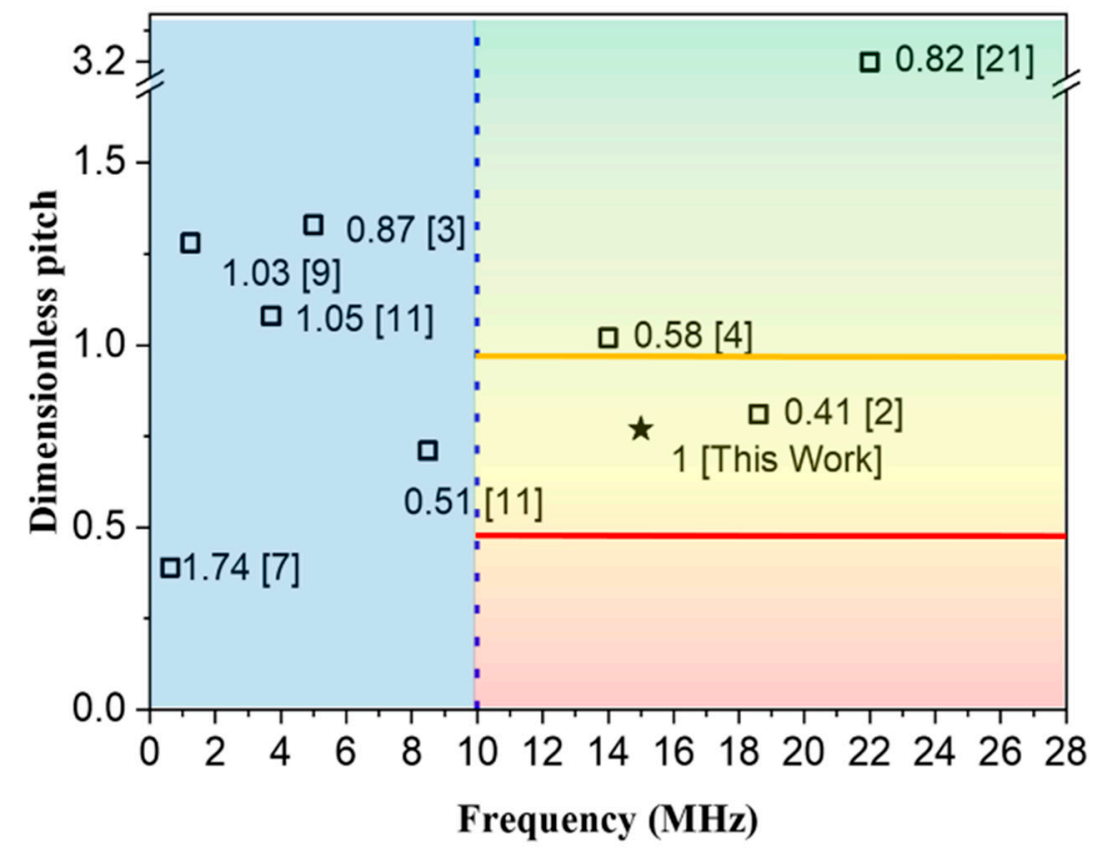

Figure 8. Comparison of working frequency, pitch, and bandwidth of different types of PMUTs under fluid load. The values in the label are the bandwidths (from references) normalized to our study. The hollow square represent the results in the published literature, and the solid star represents the results given in this study.

\section{Conclusions}

To overcome the bandwidth-pitch tradeoff of the 2D PMUTs array, we propose using a backing layer. We settle to use PDMS as the backing material because it easily fills small cavities, has an acoustic impedance close to water or human tissues, and has a strong damping effect without affecting the flexural vibration of the PMUT. After fabricating a $16 \times 8$ array with $75 \mu \mathrm{m}$ pitch $(3 \lambda / 4)$, we observe that the PDMS backing can double the bandwidth of the device with little influence on the center frequency and impulse response sensitivity. This technology is a step forward in developing a high-frequency PMUT phased array, which is expected to be widely used in superficial organ imaging, intravascular imaging, and other applications.

Author Contributions: Conceived and designed the experiments, X.-B.W. and L.-M.H.; Performed the experiments X.-B.W. and Y.-C.M.; Analyzed the data X.-B.W., W.-J.L.; Wrote the paper X.-B.W.; Review and editing W.-J.X., J.-Y.R., A.R., J.Z. All authors have read and agreed to the published version of the manuscript. 
Funding: This work is supported by the National Natural Science Foundation of China with Grant No. 61674043, 12004078, and No. 51950410582.

Institutional Review Board Statement: Not applicable.

Informed Consent Statement: Not applicable.

Data Availability Statement: Data sharing not applicable.

Conflicts of Interest: The authors declare no conflict of interest. The funders had no role in the design of the study; in the collection, analyses, or interpretation of data; in the writing of the manuscript, or in the decision to publish the results.

\section{References}

1. Davidsen, R.E.; Smith, S.W. Two-dimensional arrays for medical ultrasound using multilayer flexible circuit interconnection. IEEE Trans. Ultrason. Ferroelectr. Freq. Control 1998, 45, 338-348. [CrossRef] [PubMed]

2. Lu, Y.; Heidari, A.; Shelton, S.; Guedes, A.; Horsley, D.A. High frequency piezoelectric micromachined ultrasonic transducer array for intravascular ultrasound imaging. In Proceedings of the 2014 IEEE 27th International Conference on Micro Electro Mechanical Systems (MEMS), San Francisco, CA, USA, 26-30 January 2014; pp. 745-748.

3. Hajati, A.; Latev, D.; Gardner, D. 3D MEMS piezoelectric ultrasound transducer technology. In Proceedings of the 2013 Joint IEEE International Symposium on Applications of Ferroelectric and Workshop on Piezoresponse Force Microscopy (ISAF/PFM), Prague, Czech Republic, 21-25 July 2013; pp. 231-235.

4. Jiang, X.; Lu, Y.; Tang, H.-Y.; Tsai, J.M.; Ng, E.J.; Daneman, M.J.; Boser, B.E.; Horsley, D.A. Monolithic ultrasound fingerprint sensor. Microsyst. Nanoeng. 2017, 3, 17059. [CrossRef] [PubMed]

5. Wang, Z.; Zhu, W.; Tan, O.K.; Chao, C.; Zhu, H.; Miao, J. Ultrasound radiating performances of piezoelectric micromachined ultrasonic transmitter. Appl. Phys. Lett. 2005, 86, 033508. [CrossRef]

6. Qiu, Y.; Gigliotti, J.V.; Wallace, M.; Griggio, F.; DeMore, C.E.M.; Cochran, S.; Trolier-McKinstry, S. Piezoelectric Micromachined Ultrasound Transducer (PMUT) Arrays for Integrated Sensing, Actuation and Imaging. Sensors 2015, 15, 8020-8041. [CrossRef] [PubMed]

7. Eovino, B.E.; Akhbari, S.; Lin, L. Broadband ring-shaped PMUTS based on an acoustically induced resonance. In Proceedings of the 2017 IEEE 30th International Conference on Micro Electro Mechanical Systems (MEMS), Las Vegas, NV, USA, 22-26 January 2017; pp. 1184-1187.

8. Lu, Y.; Rozen, O.; Tang, H.-Y.; Smith, G.L.; Fung, S.; Boser, B.E.; Polcawich, R.G.; Horsley, D.A. Broadband piezoelectric micromachined ultrasonic transducers based on dual resonance modes. In Proceedings of the 2015 28th IEEE International Conference on Micro Electro Mechanical Systems (MEMS), Estoril, Portugal, 18-22 January 2015; pp. 146-149.

9. Wang, T.; Kobayashi, T.; Lee, C. Micromachined piezoelectric ultrasonic transducer with ultra-wide frequency bandwidth. Appl. Phys. Lett. 2015, 106, 054004. [CrossRef]

10. Hajati, A.; Latev, D.; Gardner, D.; Hajati, A.; Imai, D.; Torrey, M.; Schoeppler, M. Three-dimensional micro electromechanical system piezoelectric ultrasound transducer. Appl. Phys. Lett. 2012, 101, 44-54. [CrossRef]

11. Nistorica, C.; Latev, D.; Gardner, D.; Imai, D.; Daft, C. Characterization of a 3D-MEMS piezoelectric transducer for portable imaging systems. In Proceedings of the 2015 IEEE International Ultrasonics Symposium (IUS), Taipei, Taiwan, 21-24 October 2015; pp. 1-4.

12. Nistorica, C.; Latev, D.; Sano, T.; Xu, L.; Imai, D. High Frequency Piezoelectric Micromachined Transducers with Wide Bandwidth and High Sensitivity. In Proceedings of the 2019 IEEE International Ultrasonics Symposium (IUS), Glasgow, UK, 6-9 October 2019; pp. 1088-1091.

13. Kuscer, D.; Bustillo, J.; Bakarič, T.; Drnovšek, S.; Lethiecq, M.; Levassort, F. Acoustic Properties of Porous Lead Zirconate Titanate Backing for Ultrasonic Transducers. IEEE Trans. Ultrason. Ferroelectr. Freq. Control 2020, 67, 1656-1666. [CrossRef] [PubMed]

14. Du, L.; Riaud, A.; Zhou, J. Smearing Observation of Picoliter Droplets Pinning on Bio-Inspired Negative Lotus Leaf Replicas. IEEE Trans. Nanotechnol. 2020, 19, 102-106. [CrossRef]

15. Durmuş, H.O.; Karaböce, B.; Çetin, E.; Özdingiş, M.; Toprak, E.; Topşar, S.Ş.; Balc1, Ş. Investigation of the Effect of Tungsten Used in Backing Materials of Ultrasound Probes on Acoustical Parameters. In Proceedings of the 2019 IEEE International Symposium on Medical Measurements and Applications (MeMeA), Istanbul, Turkey, 26-28 June 2019; pp. 1-6.

16. Wang, X.-B.; He, L.-M.; Liu, W.-J.; Song, S.-R.; Xu, W.-J.; Cheng, Q.; Riaud, A.; Ren, J.-Y.; Zhou, J. Development of PZT-based $18 \mathrm{MHz} 2 \mathrm{D}$ pMUT array with PDMS waveguide. In Proceedings of the 2020 IEEE International Ultrasonics Symposium (IUS), Las Vegas, NV, USA, 7-11 September 2020; pp. 1-4.

17. Jung, J.; Annapureddy, V.; Hwang, G.-T.; Song, Y.; Lee, W.; Kang, W.; Ryu, J.; Choi, H. 31-mode piezoelectric micromachined ultrasonic transducer with PZT thick film by granule spraying in vacuum process. Appl. Phys. Lett. 2017, 110, 212903. [CrossRef]

18. Lu, Y.; Tang, H.; Wang, Q.; Fung, S.; Tsai, J.M.; Daneman, M.; Boser, B.E.; Horsley, D.A. Waveguide piezoelectric micromachined ultrasonic transducer array for short-range pulse-echo imaging. Appl. Phys. Lett. 2015, 106, 193506. [CrossRef]

19. Xu, G.; Ni, Z.; Chen, X.; Tu, J.; Zhang, D. Acoustic Characterization of Polydimethylsiloxane for Microscale Acoustofluidics. Phys. Rev. Appl. 2020, 13, 054069. [CrossRef] 
20. Huang, W.; Chang, W.-Y.; Kim, J.; Li, S.; Huang, S.; Jiang, X. A Novel Laser Ultrasound Transducer Using Candle Soot Carbon Nanoparticles. IEEE Trans. Nanotechnol. 2016, 15, 395-401. [CrossRef]

21. Lu, Y.; Tang, H.; Fung, S.; Wang, Q.; Tsai, J.M.; Daneman, M.J.; E Boser, B.; A Horsley, D. Ultrasonic fingerprint sensor using a piezoelectric micromachined ultrasonic transducer array integrated with complementary metal oxide semiconductor electronics. Appl. Phys. Lett. 2015, 106, 263503. [CrossRef]

22. Schmerr, L.W. Fundamentals of Ultrasonic Phased Arrays. Micromech. Mater. Appl. 2015, 215, 73-98. 